\title{
A Relação entre Clima Organizacional e a Prestação do Serviço de Qualidade na Universidade Pública
}

Jérsica Florindo de Araújo Barros ${ }^{1}$; Milka Alves Correia Barbosa ${ }^{2}$

\begin{abstract}
Resumo: Este artigo teve como objetivo analisar de que forma o clima organizacional relaciona-se à prestação do serviço de qualidade em uma universidade pública. Para tanto, foi realizado um estudo de caso no Campus Sertão da Universidade Federal de Alagoas (UFAL). Para coletar dados, aplicou-se questionários com os servidores técnico-administrativos da instituição. Considerando-se os dados analisados, foi possível concluir, à luz de Siqueira (2008), que os fatores controle/pressão e coesão sinalizam um clima organizacional favorável, enquanto o fator recompensa aponta para um clima desfavorável e os fatores apoio da chefia/instituição e conforto físico assumiram caráter neutro. Também foi possível identificar que os principais elementos influenciadores na qualidade da prestação do serviço coincidem com os fatores que apontam o clima organizacional, configurando uma aproximação entre ambos. Espera-se que os dados aqui revelados possam proporcionar subsídios para ação interventiva sobre esses fatores, tanto por uma iniciativa pessoal, como por uma iniciativa da instituição
\end{abstract}

Palavras-Chave: clima organizacional, universidade, qualidade na prestação de serviço.

\section{The Relationship between Organizational Climate and Quality of Service Provision in Public University}

\begin{abstract}
This article aims to analyze how the organizational climate relates to the provision of quality service at a public university. Therefore, we conducted a case study in Campus do Sertão of Universidade Federal de Alagoas (UFAL). To collect data, applied questionnaires with the technical-administrative staff of the institution. Considering the data analyzed, it was concluded, in the light of Siqueira (2008), the control/pressure and cohesion factors indicate a favorable organizational climate, while the reward factor points to an unfavorable climate and the supporting the head/institution and physical comfort factors assumed neutral character. It was also possible to identify the key influencers elements in the quality of service provision coincide with the factors that link the organizational climate by setting up a connection between both. It is expected that the data disclosed herein can provide subsidies to interventional action on these factors, both on a personal initiative, such as an initiative of the institution.
\end{abstract}

Keywords : organizational climate, university, quality in service delivery .

\section{Introdução}

Compreender as relações de trabalho nas organizações constitui um passo importante para garantir a prestação de serviços baseados na efetividade e excelência. Nesse sentido, Chiavenato (2010) justificou tal relevância defendendo que as organizações permeiam o mundo dos negócios e constituem o motor do desenvolvimento social, econômico, financeiro e tecnológico da sociedade moderna.

\footnotetext{
${ }^{1}$ Graduação em Letras com Habilitação em português e Inglês - Faculdade Sete de Setembro-FASETE; Especialista em Língua Portuguesa e Literatura -Faculdade São Luís de França; Técnica-Administrativa na Universidade Federal de Alagoas-UFAL.

${ }^{2}$ Doutora e Mestre em Administração pela PROPAD/Universidade Federal de Pernambuco - UFPE, Professora adjunta da Universidade Federal de Alagoas, Campus de Arapiraca. Curso de Administração. E-mail: milka.barbosa@univasf.edu.br.
} 
Id on Line Revista Multidisciplinar e de Psicologia

Id on Line Revista Multidisciplinar e de Psicologia

Atualmente, temáticas como a qualidade na prestação do serviço, a transparência administrativa e novas formas de organização do trabalho têm constituído preocupação para quem estuda as organizações e almeja efetividade na prestação de serviço. Segundo Pires e Macêdo (2006), as organizações se deparam com a necessidade do novo, tanto em aspectos políticos, quanto em administrativos. Mais do que isso, precisam integrar aspectos políticos e técnicos, sendo essa junção inerente e fundamental para as ações.

Nessa discussão, estão inseridos todos os tipos de organizações, inclusive as universidades. Schacknow (2008) assegura que universidades são organizações complexas, pois apesar de exibirem as mesmas características e necessidades dos demais tipos de organizações, seus processos e demandas são diferenciadas, tornando-as organizações únicas, as quais diferem de organizações industriais, órgãos governamentais e empresas de serviços.

Diante dessa complexidade, considera-se relevante manter o clima organizacional saudável, contribuindo para a satisfação dos seus múltiplos usuários, em especial daqueles servidores que atuam nas funções administrativas das universidades (ESTRADA, 2000).

Analisando o clima organizacional em universidades brasileiras, Rizzatti (2002) mostrou que o controle da qualidade dos serviços, dentre outros componentes, é determinante na identificação de problemas, visando à implementação de ações que possam melhorar a instituição universitária.

O presente trabalho está organizado em três seções, além dessa introdução. Na primeira seção, aborda-se questões que caracterizam o clima organizacional, na sequência, aborda-se a universidade como um tipo especial de organização. Em seguida, descrevem-se os aspectos metodológicos da presente investigação, para finalmente apresentar os resultados.

\section{Clima organizacional}

Clima organizacional é entendido como o conjunto das percepções compartilhadas pelos trabalhadores, desenvolvidas através das suas relações com as políticas, práticas e procedimentos organizacionais (SIQUEIRA, 2008). Trazendo essa discussão para o contexto das universidades, argumenta-se que o processo de busca por um ambiente propício para a prestação de serviço eficiente se apoia na compreensão do clima organizacional (SCHACKNOW, 2008).

Na concepção de Moro et al. (2012), “o clima organizacional explicita a atmosfera íntima de uma instituição e abrange a relação dos itens que influenciam o ambiente e afetam direta ou indiretamente o comportamento das pessoas no trabalho" (MORO ET AL. 2012, P. 03).

Rizzatti et al. (2010) apresenta duas possibilidades de entendimento acerca do clima organizacional: uma considerando-o como um conjunto de características que descrevem uma 
Id on Line Revista Multidisciplinar e de Psicologia

Id on Line Revista Multidisciplinar e de Psicologia

organização, e outro referindo-se a ele como um conjunto de valores ou atitudes que afetam o relacionamento das pessoas.

Com entendimento semelhante ao de Siqueira (2008), Neves (2009) concluiu que o clima de uma organização se trata de percepções compartilhadas. Isto é, as ideias que os colaboradores de uma organização compreendem como uma percepção do grupo, através da interação dos membros com o ambiente de trabalho são a essência do construto clima organizacional. Assim sendo, segundo ele é mais fácil perceber o clima organizacional como favorável ou não, do que identificar os fatores mantenedores do próprio clima.

De acordo com Luz (2003, p.46), existem dois tipos de clima organizacional: "O clima é bom quando predominam as atitudes positivas que dão ao ambiente de trabalho uma tônica favorável e é prejudicado ou ruim quando algumas variáveis organizacionais afetam de forma negativa e duradoura o ânimo da maioria dos funcionários". Já Chiavenato (2004) usou expressões como "positivo e negativo', 'quente e frio', 'agradável e desagradável', 'amigável e adverso'. Com isso, infere-se existir um consenso quanto a esses extremos, sendo de um lado um clima favorável, do outro um clima desfavorável. No entanto, ainda pode-se encontrar registros de uma condição de neutralidade do clima organizacional, a exemplo do trabalho de Bispo (2006).

É possível encontrar elementos que podem constituir o clima organizacional, quais sejam, a cultura organizacional, a forma como a instituição é percebida pelos seus membros, o grau de motivação, a produtividade e a satisfação dos indivíduos, ou ainda as relações interpessoais (MORO et al, 2012).

Como Moro et al. (2012), muitos pesquisadores têm estudado o clima das organizações atrelada a motivação de seus colaboradores, dentre eles, Rizzatti (2002) afirma que "o termo clima organizacional refere-se especificamente às propriedades motivadoras do ambiente organizacional, isto é, àqueles aspectos que levam a despertar de diferentes tipos de motivação" (RIZZATTI, 2002, p. 27).

Na mesma perspectiva, Costacurta (2010) afirma que o clima envolve o grupo de pessoas que constituem a organização e que pode afetar diretamente a motivação e o desempenho. Assim sendo, não se pode negar o impacto que a motivação de um determinado grupo, individual ou coletivamente exerce sobre o clima organizacional. Sendo assim, para entender tal relação, se faz necessário compreender os aspectos motivadores das pessoas.

Além da motivação, Moro et al. (2012) relaciona o clima organizacional com o conceito de cultura organizacional. Por isso, também é importante fazer algumas considerações sobre essa relação. Segundo Chiavenato (2004, p. 165), a cultura organizacional "se refere ao sistema de significados compartilhados por todos os membros de uma empresa". Todo aparato de signos e significados que uma empresa possui em termos de ideias, costumes, regras e técnicas constituem exatamente o universo da cultura organizacional de uma empresa. 
Id on Line Revista Multidisciplinar e de Psicologia

Id on Line Revista Multidisciplinar e de Psicologia

Assim, infere-se que o clima organizacional é mutável, pois depende de vários fatores, entre eles a motivação, a satisfação das pessoas e a atmosfera de suas relações. Já a cultura é mais durável, pois decorre de práticas estabelecidas ao longo do tempo.

Outro componente destacado por Moro et al. (2012) que traz estrita relação com o clima organizacional são as relações interpessoais. Segundo eles, o relacionamento interpessoal avalia a qualidade das relações pessoais entre funcionários, entre eles e suas chefias, entre os funcionários e a empresa e a existência e intensidade de conflitos.

Todos esses fatores influenciam na identificação do clima de uma organização. No entanto, quando se pensa em suas aplicações em relação às organizações de serviço que atuam na área da educação superior, como as universidades, seus efeitos podem ser bastante singulares (SILVA, 2001). Por esse motivo, faz-se necessário abordar esse 'tipo' de organização tão peculiar de forma que se possa caracterizá-la, para que sua missão se faça clara.

\section{A Universidade}

A universidade é uma instituição que objetiva a disseminação do conhecimento e da ciência, por meio da formação de especialistas, contribuindo para o desenvolvimento do ser humano enquanto ser social. Conforme Rocha (2014), a universidade é uma instituição social preparada para atender as necessidades sentidas pelo povo. Estas necessidades, por sua vez dão espaços para que estudiosos e pesquisadores aprofundem seu trabalho em busca de soluções que sejam relevantes à sociedade em geral (ROCHA, 2014, p. 01).

Conforme Camacho (2005), a universidade é um lugar para conhecimento da cultura universal e das várias ciências, que deve buscar uma identidade própria e uma adequação à realidade nacional. Nesse sentido, suas finalidades básicas são o ensino, a pesquisa e extensão, ou seja, trata-se de uma instituição social que forma, de maneira sistemática e organizada, os profissionais técnicos e intelectuais de nível superior que a sociedade necessita.

Do ponto de vista da configuração organizacional, a universidade é um tipo bastante singular, especialmente quando comparada à outras organizações, pois se trata de uma estrutura complexa que demanda análise diferenciada. Autores como Schacknow (2008) e Silva (2001) concordam quanto à complexidade dessa organização. Especificamente Falqueto (2012) identificou o principal motivo que atribui esse caráter complexo às universidades:

$\mathrm{O}$ fato de as universidades serem organizações voltadas à transmissão e produção do conhecimento conforma um padrão típico para a estruturação de suas atividades. Essa inclusive é uma das razões pelas quais a universidade não pode ser vista pela mesma ótica das demais iniciativas empresariais (FALQUETO, 2012, p. 16) 
Para além desses fatores, Falqueto (2012), estudando Baldridge (1983), identificou outras características que peculiarizam as universidades, as quais podem ser visualizadas no quadro 01 :

Quadro 01: Peculiaridades das universidades como organizações

\begin{tabular}{|c|l|}
\hline Características da Universidade & \multicolumn{1}{|c|}{ Descrição } \\
\hline Objetivos ambíguos e difusos & $\begin{array}{l}\text { o trabalho realizado pelas universidades aponta para várias } \\
\text { direções, mas não há um foco específico, o que dificulta o } \\
\text { planejamento e a tomada de decisão; }\end{array}$ \\
\hline Natureza política & $\begin{array}{l}\text { há muitos grupos de interesses com objetivos e valores distintos no } \\
\text { ambiente universitário, e as decisões são fruto de negociação entre } \\
\text { esses grupos; }\end{array}$ \\
\hline $\begin{array}{c}\text { Usuários com necessidades } \\
\text { individualizadas e diversificadas }\end{array}$ & $\begin{array}{l}\text { os grupos que utilizam os serviços das universidades possuem voz } \\
\text { ativa no processo decisório; }\end{array}$ \\
\hline Tecnologia complexa & $\begin{array}{l}\text { como os clientes são distintos entre si, as universidades necessitam } \\
\text { de métodos, processos e tecnologias diversificadas para atender às } \\
\text { diferentes demandas; }\end{array}$ \\
\hline $\begin{array}{c}\text { Sensibilidade a fatores } \\
\text { do ambiente externo }\end{array}$ & $\begin{array}{l}\text { a rapidez com que determinados conhecimentos se tornam } \\
\text { obsoletos obrigam as universidades a se manterem atualizadas e } \\
\text { atentas às mudanças, adaptando-se sempre que necessário. }\end{array}$ \\
\hline
\end{tabular}

Fonte: Elaborado com base em Falqueto (2012) apud Baldridge (1983)

Diante de tais características, admite-se que um dos caminhos que podem levar à harmonia das relações e desenvolvimento de ações na universidade está na manutenção de um clima organizacional propício, devendo, para tanto, ser reconhecido as demandas internas e a realidade vivenciada pelos que a compõem.

\section{Metodologia da Pesquisa}

Apresente pesquisa caracteriza-se como exploratória, poisbuscou avaliar os conceitos que precisavam ser explicados para elucidar a relação de clima e qualidade na prestação do serviço especificamente no Campus do Sertão/UFAL.

É possível ainda descrevê-la como um estudo de caso, que conforme Ruiz (2002, p. 41) "é uma estratégia de pesquisa que busca examinar um fenômeno contemporâneo dentro de seu contexto". Na pesquisa em questão, o caso foi direcionado ao clima organizacional na Ufal/Campus Sertão. 
Id on Line Revista Multidisciplinar e de Psicologia

Id on Line Revista Multidisciplinar e de Psicologia

Segundo Lakatos e Marconi (2001, p.165) a coleta de dados é uma "etapa de pesquisa em que se inicia a aplicação dos instrumentos elaborados e das técnicas selecionadas, a fim de se efetuar a coleta dos dados previstos". Assim, inicialmente foi realizada uma pesquisa bibliográfica em artigos, livros, revistas especializadas e também em sites da internet com o intuito de encontrar publicações que pudessem embasar a pesquisa em questão.

Após a pesquisa bibliográfica, iniciou-se a pesquisa de campo, na qual foi aplicado um questionário semiestruturado com questões fechadas para caracterização do clima, mas também uma questão aberta, onde o respondente teve a oportunidade de citar os fatores que considerava como primordiais para a garantia da qualidade na prestação do serviço.

O questionário baseou-se na Escala de Clima Organizacional-ECO proposta por Siqueira (2008). A ECO trata-se de uma escala multidimensional construída e validada com o objetivo de avaliar a percepção do trabalhador sobre várias dimensões do clima organizacional, composta por 63 itens agrupados em 5 fatores: Apoio da chefia e da organização (Fator 1, com 21 itens), Recompensa (Fator 2, com 13 itens), Conforto Físico (Fator 3, com 13 itens), Controle/Pressão (Fator 4, com 9 itens) e Coesão entre colegas (Fator 5, com 7 itens).

Assim, os técnicos do Campus do Sertão/UFAL receberam um questionário com 63 questões fechadas, onde teriam de marcar de 1 a 5 em cada uma delas, sendo que dentro da escala 1 o respondente discordava totalmente da afirmativa e 5 concordava totalmente. A coleta de dados deu-se no mês de abril de 2016.

O universo da pesquisa abrangeu o quadro de quarenta e dois técnicos-administrativos efetivos do Campus do Sertão; destes trinta e um estão lotados na Sede de Delmiro Gouveia e onze na Unidade de Santana do Ipanema. O grupo de participantes do estudo foi selecionado por conveniência. Guimarães (2008, p. 18, grifo do autor) define que "a amostra de conveniência é formada por elementos que o pesquisador reuniu simplesmente porque dispunha deles". Pode ainda afirmar que os participantes da pesquisa foram selecionados pela facilidade de acesso e tipicidade, elementos que os pesquisadores consideraram representativo da população-alvo, Vergara (2004) define esses elementos como, elementos pela facilidade de acesso e elementos que o pesquisador considere representativo da população-alvo.

Considerando os servidores impossibilitados de responder ao questionário, por se encontrarem de férias e de licença, a amostra totalizou 32 respondentes, destes 26 lotados em Delmiro Gouveia e 06 em Santana do Ipanema, representando $76,2 \%$ da população da pesquisa.

Quanto à técnica de análise dos dados, como a ECO é uma escala composta por cinco fatores, os resultados foram apurados por fator. Assim, a média fatorial pode ser interpretada como: menor que 3,0 corresponde aos que discordam ou discordam totalmente dos itens; de 3,0 a 3,5 corresponde aos que nem concordam, nem discordam; acima de 3,5 correspondem aos que concordam ou concordam totalmente. 
Id on Line Revista Multidisciplinar e de Psicoloqia

Id on Line Revista Multidisciplinar e de Psicologia

\section{Análise dos Dados}

\section{O clima organizacional na UFAL/Campus do Sertão}

A pesquisa em questão foi realizada com servidores técnico-administrativos da UFAL/ Campus Sertão, cujo perfil pode ser assim descrito: $41 \%$ mulheres, $59 \%$ homens, $78 \%$ com nível superior, $22 \%$ de nível médio, 37,5\% efetivos e 62,5\% em estágio probatório. Observe-se que o número de servidores em estágio probatório é maior que os efetivos, isso se deve ao fato do Campus do Sertão/UFAL ter sido criado a pouco tempo, apenas há seis anos, incentivado pelo Programa do Governo Federal de Apoio a Planos de Reestruturação e Expansão das Universidades Federais Brasileiras (REUNI).

Em referência ao Fator apoio da chefia e da organização proposto por Siqueira (2008) e corresponde ao suporte afetivo, estrutural e operacional da chefia e da organização, fornecido aos servidores técnico-administrativos do Campus do Sertão/UFAL no desempenho diário de suas atividades, observa-se no gráfico 01 , a média dos vinte um fatores que referem-se ao suporte da chefia alcançou proporção razoavelmente favorável, se comparado com o escore demonstrado para os que discordaram da existência do apoio. Em Delmiro, 39\% dos técnicos avaliaram que há esse suporte, frente a $23 \%$ dos que discordaram. Da mesma forma, em Santana do Ipanema 17\% perceberam o apoio institucional, diante de nenhuma discordância.

\section{Gráfico 1: Fator Apoio da chefia e da organização}

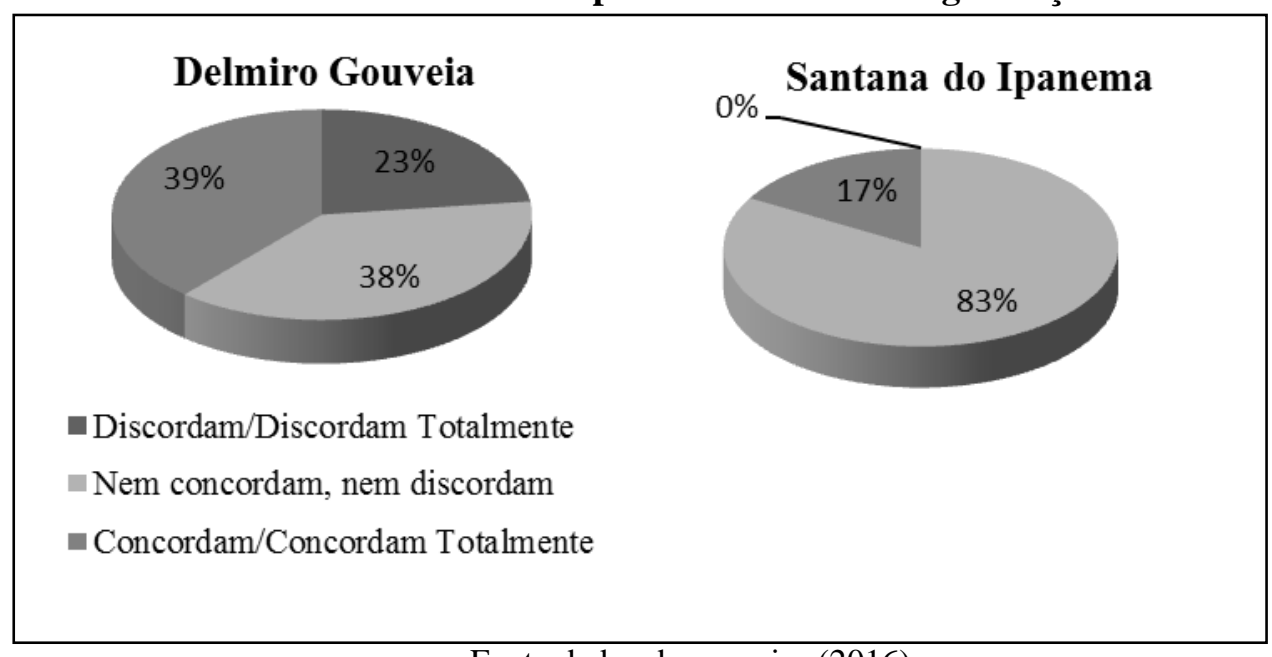

Fonte:dados da pesquisa (2016).

No entanto, vale registrar a expressiva porcentagem dos indiferentes: $38 \%$ em Delmiro e $83 \%$ em Santana.Esse dadonão significa que o apoio da chefia e/ou da instituição inexista; pode ser que esse apoio não seja tão marcante a ponto de ser percebido pelos respondentes. O impacto disso sobre o 
Id on Line Revista Multidisciplinar e de Psicologia

Id on Line Revista Multidisciplinar e de Psicologia

clima organizacional não determina resultados positivos ou negativos, mas é pertinente recordar que segundo Bispo (2006), a indiferença e a apatia são determinantes de um clima mais ou menos.

Vale registrar ainda que os itens responsáveis pela média baixa no Fator 01 foram o 04, 08 e 13 que correspondiam, respectivamente, as tarefas que demoram mais para serem realizadas são coordenadas até o fim pelo chefe, as mudanças nesta instituição são informadas aos servidores e as inovações propostas pelo servidor são aceitas pela instituição. Assim, compreende-se que no Campus do Sertão, as atividades de longo prazo precisam ser melhor acompanhadas e as ações que envolvem mudanças precisam ser melhor planejadas.

Com relação ao item que atribuiuao Fator 01 os maiores escores, cita-se o item 21 - $O$ diálogo é utilizado para resolver problemas. Esse dado revela o potencial que o Campus do Sertão/UFAL tem para melhorar a percepção do clima organizacional, por meio dessa ferramenta interativa que é o diálogo, no suporte da relação servidor/chefia e servidor/instituição, alinhando a ideia de Chiavenato (2003) de que é pelo processo de comunicação que o sistema cooperativo se torna dinâmico, facilita a tomada de decisão e reflete o clima harmonioso no ambiente da instituição

Em se tratanto de recompensas usadas pela instituição para premiar a qualidade, a produtividade, o esforço e o desempenho do servidor técnico, o gráfico 2 mostra que a grande maioria dos respondentes considera o fator recompensa como um aspecto presente no Campus do Sertão.

Em Santana do Ipanema, observa-se que 67\% dos respondentes discordam que o sistema de recompensas seja decisivo no desempenho do trabalho e em Delmiro Gouveia esse número chega a 77\%. À luz da ECO, as recompensas bem administradas são os mecanismos para criar tanto a satisfação quanto um alto desempenho na força de trabalho. Concordando, Chiavenato (2003) já tem posto que o alcance de resultados estimula a recompensa e os incentivos e quando estimulada, essa dimensão impulsiona um clima organizacional favorável.

\section{Gráfico 2: Fator Recompensa}
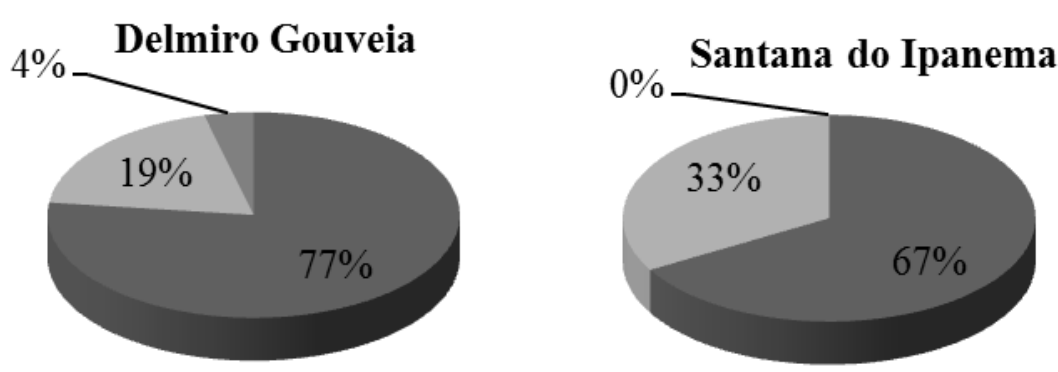

- Discordam/Discordam Totalmente

- Nem concordam, Nem discordam

- Concordam/Concordam Totalmente

Fonte:dados da pesquisa (2016) 
Nesse sentido, com base nos altos escores de discordância, é possível considerar que, no Campus do Sertão, o fator recompensa pode contribuir para um clima organizacional desfavorável.Essa constatação, se deveu ainda ao consenso entre os servidores de que seus salários não dependem de sua produtividade, baseado nos baixos índices no resultado dos itens 32 (A produtividade do servidor tem influência no seu salário) e 33 (A qualidade do trabalho tem influência no salário).

Tratando de conforto físico, o gráfico 3mostra que em Santana do Ipanema $83 \%$ dos respondentes concordam que a Unidade não dispõe de instalações que proporcionem um conforto físico aos servidores. Esse dado é preocupante pois, se os servidores se mostram insatisfeitos com as consições físicas, o reflexo disso para a imagem da instituição não é bom. Moro et al. (2012) já compreendiam queo clima organizacional representa a imagem da universidade.

\section{Gráfico 3: Fator Conforto Físico}

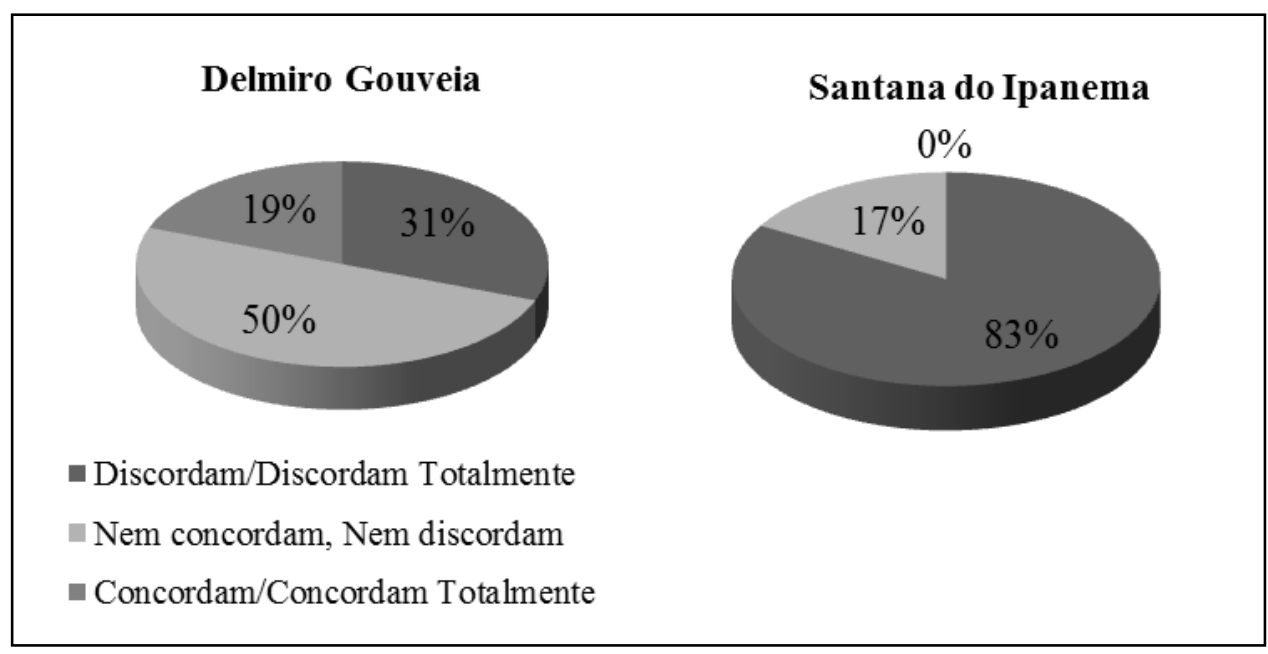

Fonte:dados da pesquisa (2016).

Quanto à avaliação dos técnicos em Delmiro Gouveia sobre o fator conforto físico, observa-se que a soma dos que concordam que o ambiente é confortável com os que concordam totalmente (19\%) é inferior aos que discordam da existência desse conforto (31\%). Ou seja, há um desacordo entre os dados coletados com servidores de Santana do Ipanema - que apresentaram índices indicativos de um clima organizacional ruim, e os servidores de Delmiro Gouveia, que apresentaram índices de um clima organizacional neutro. Pode-se afirmar sobre o fator conforto físico que há uma indicação de neutralidade sobre o clima organizacional, sem que esse aspecto seja influência nem positiva, nem negativa para o clima.

Sobre o fator controle/pressão exercidos pela instituição e pelos supervisores/chefia sobre o comportamento e desempenho dos servidores, observa-se que $76 \%$ dos respondentes discordaram da 
Id on Line Revista Multidisciplinar e de Psicoloqia

Id on Line Revista Multidisciplinar e de Psicologia

existência de pressão exercida por parte da instituição/chefia sobre os servidores e $22 \%$ se mostraram indiferentes à ocorrência desse controle.

Observe-se que, em todos os outros fatores quanto maior o valor da média fatorial, melhor é o clima organizacional. No entanto, no Fator Controle/Pressão, quanto maior o resultado, pior é o clima porque maior é o controle e a pressão exercidos sobre os servidores. Nesse sentido, os dados coletados indicam que média fatorial geral nesse fator 04 foi de 2,4, expressa numa média baixa, mas indicativa de um bom clima organizacional.

Verifica-se que os itens relacionados ao controle exagerado, à utilização de regras para punições e pressão constante da chefia, obtiveram números baixos, confirmando a discordância dos técnicos no Campus do Sertão com relação à incidência de cobranças e pressões no ambiente de trabalho. É possível admitir que esse aspecto contribui para a manutenção de um clima organizacional favorável, ao contrário de ambientes de trabalho nos quais há forte pressão para o cumprimento de normas bastante rígidas, burocráticas, cujos resultados podem levar à punições, o clima organizacional é caracterizado como tenso (SOUZA; GARCIA, 2011).

Abordando-se a coesão entre colegas, avaliando a união, os vínculos e colaboração entre os colegas de trabalho, na opinião da maioria dos respondentes, $92 \%$ em Delmiro e $83 \%$ em Santana, o Campus do Sertão constitui um ambiente organizacional onde as relações são agradáveis. Assim, há consenso entre os respondentes que as relações são de amizade, que existe cooperação e integração entre os colegas e que novos servidores são bem recebidos quando chegam ao ambiente de trabalho no Campus do Sertão.

Desta forma, os dados da pesquisa sobre o fator 05 são animadores, pois revelam que as relações influenciam positivamente no clima organizacional do Campus do Sertão. Nesse sentido, Rizzatti (2002) já havia observado a necessidade de basear as relações de trabalho na cooperação, defendendo ser ponto chave para o desenvolvimento das qualificações dos servidores e para resolver problemas no ambiente de trabalho, refletindo assim no clima organizacional da instituição.

Numa avaliação mais detalhada, obtem-se a média geral para cada um dos fatores propostos: Apoio da chefia/instituição - Média fatorial: 3,3; Recompensa - Média fatorial: 2,4; Conforto Físico Média fatorial: 3,1; Controle/Pressão - Média fatorial: 2,4; e Coesão entre colegas - Média fatorial: 4,0. Observe-se queos fatores controle/pressão e coesão entre Colegas contribuem para um clima organizacional favorável enquanto, em direção contrária, está o fator Recompensa. Já osfatores Apoio da chefia/instituição e Conforto Físico assumem caráter neutro. 
Id on Line Revista Multidisciplinar e de Psicologia

Id on Line Revista Multidisciplinar e de Psicologia

\section{Elementos influenciadores na qualidade da prestação do serviço: a percepção dos técnicos- administrativos da Ufal/Campus Sertão}

No questionário aplicado aos técnicos do Campus do Sertão, além se abordar aspectos do clima organizacional, também se inseriu uma questão para averiguar junto aos respondentes os elementos influenciadores na qualidade da prestação do serviço, verificar uma possível relação entre eles e os elementos apontados na caracterização do clima organizacional no Campus do Sertão.

Aqui cabe revelar que durante essa etapa da análise de dados foi possível identificar duas categorias de elementos presentes nas falas dos respondentes, quais sejam os pessoais - que se considerou como sendo aqueles que dependem da atitude pessoal do servidor, e os institucionais aqueles que dependem da ação institucional, no sentido de prover condições de trabalho.

Assim, quanto aos elementos pessoais, foram apontados pelosservidores do Campus do Sertão/UFAL, a proatividade, o bom senso, companheirismo, ética pessoal, responsabilidade, comunicação/diálogo, bom atendimento, clareza nas informações, consciência do serviço público e comprometimento pessoal; esse último com maior ênfase, como se pode observar nos trechos a seguir: Atualmente não existe (01) um fator/métrica quantitativo ou qualitativo que garanta a qualidade. $O$ que a mantêm é a ética para com os princípios da administração, prestatividade e disposição dos servidores.(servidor A); Apenas meu próprio desempenho. (servidor B); Em primeiro lugar , o meu comprometimento com aquilo que fui contratado para fazer, depois as condições oferecidas para realizá-la. (servidor C); O clima de cooperação e o diálogo para busca de alternativas para a solução de problemas. (servidor D); $O$ que garante a qualidade é a comunicação, através de informações e principalmente diálogo entre o grupo e também entre o chefe. (servidor E)

Com relação aos elementos institucionais, foram citados a autonomia, descentralização, ética institucional, planejamento, sistema de informações, condições de trabalho, estrutura física e material, treinamento, capacitação e recursos humanos. Desses, os mais enfatizados foram as condições de trabalho e o treinamento/capacitação de servidor, como demonstram respostas a seguir: Educação continuada, responsabilidade e acima de tudo companheirismo. (Servidor F); Investimento na formação continuada do servidor - capacitação e qualificação. (Servidor G); Comprometimento dos servidores, ferramentas de trabalho adequadas e sistemas de informação que forneçam respostas rápidas, confiáveis e precisas. (Servidor $H$ )

Observando a literatura e os elementos citados pelos respondentes como garantia para a qualidade na prestação do serviço, é possível associá-los a um clima organizacional harmonioso. Sampaio (2014), analisando os fatores que influem na qualidade do ensino, já havia observado por exemplo a presença da motivação (de alunos, servidores, professores, etc) para a excelência dos recursos físicos e humanos. 
Id on Line Revista Multidisciplinar e de Psicologia

Id on Line Revista Multidisciplinar e de Psicologia

Sampaio (2014) também havia entendido a qualidade das ações no trabalho atrelado a boas condições de trabalho. As respostas dos respondentes do Campus Sertão, quando identificam os elementos pessoais e institucionais citados, concordam com o entendimento de Sampaio (2014) sobre as condições de trabalho, através da garantia, por exemplo, de bons equipamentos e métodos de informação e, consequentemente, da garantia de fatores que mantêm a harmonização do clima organizacional.

Assim, tanto os elementos pessoais como os elementos institucionais, citados pelos respondentes, em associação à qualidade na prestação de serviço no Campus do sertão/UFAL, constituem elementos que coincidem com os fatores determinantes do clima organizacional. Portanto, mantêm relação direta com o próprio clima de uma instituição, ou seja, os aspectos relacionados ao clima organizacional contribuem para melhoria da qualidade dos serviços prestados à comunidade.

\section{Considerações Finais}

O clima organizacional foi caracterizado com base em cinco fatores influenciadores: apoio da chefia, recompensa, conforto físico, pressão/controle e coesão entre colegas.Verificou-se que a pesquisa sobre o fator apoio da chefia revelou certa neutralidade de influência sobre o clima organizacional, pois não determinou índices indicativos de discordância, mas também não gerou resultados de concordância sobre o suporte chefia/instituição. Com relação ao fator recompensa, foi coerente considerá-lo como determinante de um clima organizacional desfavorável, indicados pelos altos escores de discordância. Quanto ao fator conforto físico, os dados revelaram a influência negativa do fator sobre o clima organizacional em Santana do Ipanema e neutra em Delmiro Gouveia. Já os dados sobre pressão/controle registraram que o fator contribui fortemente para a manutenção de um clima organizacional favorável. Da mesma forma, os dados da pesquisa do fator coesão entre colegas são muito bons, pois revelam que as relações influenciam positivamente no clima organizacional do Campus do Sertão.

Em síntese, considerando o percentual de clima organizacional proposto por Siqueira (2008), os fatores controle/pressão e coesão entre Colegas determinam um clima organizacional favorável, o fator recompensa determina um clima desfavorável e os fatores apoio da chefia/instituição e conforto físico não trazem nenhum tipo de determinação por seu caráter neutro. Assim, resumidamente, pode-se dizer que o clima organizacional no Campus do Sertão tende a ser bom, mas pode ser melhor se os fatores neutros forem trabalhados.

Tratando dos elementos influenciadores na qualidade da prestação do serviço, com os dados analisados, também foi possível defini-los em elementos pessoais e institucionais. Quanto aos elementos pessoais pontuados pelos servidores do Campus do Sertã/UFAL, registre-se a proatividade, 
Id on Line Revista Multidisciplinar e de Psicologia

Id on Line Revista Multidisciplinar e de Psicologia

o bom senso, companheirismo, ética pessoal, responsabilidade, comunicação/diálogo, bom atendimento, clareza nas informações, consciência do serviço público e comprometimento pessoal. Com relação aos elementos institucionais, foram citados a autonomia, descentralização, ética institucional, planejamento, sistema de informações, condições de trabalho, estrutura física e material, treinamento, capacitação e recursos humanos. Concluiu-se que, tanto os elementos pessoais como os elementos institucionais citados pelos respondentes associam-se à qualidade na prestação de serviço no Campus do sertão/UFAL, pois coincidem com os fatores determinantes do clima organizacional.

Sendo assim, os dados mostraram que os fatores mantenedores de um clima favorável são adjacentes dos elementos que garantem a qualidade na prestação do serviço.

Espera-se que os dados aqui revelados possam proporcionar ao Campus do Sertão/UFAL e aos servidores técnicos a possibilidade de crescimento, através, inicialmente, da observação daqueles fatores que foram avaliados como determinantes de um clima organizacional desagradável e, posteriormente, da ação interventiva sobre esses fatores, tanto por uma iniciativa pessoal, como por uma iniciativa da instituição. Assim, a probabilidade de avanços, em todos os aspectos considerados influenciadores de um clima organizacional harmonioso, só aumenta e favorece a manutenção de uma equipe que consegue cooperar mutuamente.

Acredita-se que a análise do clima organizacional, por meio dos dados identificados, seja um meio eficiente para a melhoria das condições necessárias ao atendimento. Assim, entende-se que a manutenção de um clima organizacional favorável - através de aspectos que zelam pela gestão comprometida, relações cooperativas entre colegas, condições físicas e humanas - é um fator que deve ser considerado nas instituições, pois afeta a motivação dos servidores. Quando o clima organizacional não é apropriado, pode ocasionar a insatisfação dos servidores, afetando, inclusive, o seu desempenho e o comprometimento na execução de suas atividades. É justamente a produtividade do servidor, decorrente de um clima organizacional leve, que garantirá a qualidade na prestação do serviço, fazendo com que as instituições públicas de ensino alcancem suas metas e objetivos.

\section{Referências}

CAMACHO, Thimoteo. A universidade pública no Brasil. Revista de Sociologia N. 19 - 2005. p. 100-133.

CHIAVENATO, Idalberto. Introdução à teoria geral da administração: uma visão abrangente da moderna administração das organizações. Edição compacta. $3^{a}$ ed. rev. e atualizada - Rio de Janeiro: Elsevier, 2004.

2003.

Administração de Recursos Humanos: fundamentos básicos. 5. ed. - São Paulo: Atlas, 
Id on Line Revista Multidisciplinar e de Psicoloqia

Id on Line Revista Multidisciplinar e de Psicologia

Iniciação à teoria das organizações. Barueri, SP; Manole, 2010.

BISPO, C. A. F. Um novo modelo de pesquisa de clima organizacional. Revista Produção, Ago 2006, vol.16, no. 2. Disponível em: Acesso em: 15/03/2016

COSTACURTA, Jaisson Rodrigo Costa. O Processo de implantação da pesquisa de clima organizacional numa instituição de ensino superior - O Caso da Universidade Católica de Brasília (UCB). Artigo. Universidade Católica de Brasília: Brasília, 2010.

ESTRADA, R. J. S. Os rumos do planejamento estratégico na universidade pública: um estudo de caso na Universidade Federal de Santa Maria. 2000. 206f. Tese (Doutorado em Engenharia de Produção) - Centro Tecnológico, Universidade Federal de Santa Catarina, Florianópolis, SC, 2000.

FALQUETO, Júlia Maria Zandonade. A implantação do planejamento estratégico em universidades: o caso da Universidade de Brasília. Dissertação. Universidade de Brasília, Faculdade de Economia, Administração e Contabilidade. Brasília, 2012.

LAKATOS, Eva Maria; MARCONI, M. A. Fundamentos da Metodologia Científica. - 4ed. rev. e ampl. - São Paulo: Atlas, 2001.

LUZ, Silveira Ricardo. Gestão do Clima Organizacional: Proposta de critérios pra metodologia de diagnóstico, mensuração e melhoria. UFF: Niterói, 2003. Disponível em: http://www.bdtd.ndc.uff.br/tde_arquivos/14/TDE-2007-06-01T102808Z-

822/Publico/Dissertacao\%20Ricardo\%20Luz.pdf Acesso em: 18/01/2016.

MORO, A. B; BALSAN, Laércio A. G; COSTA, Vânia M. F; COSTA, V. F; e SCHETINGER, Maria Rosa C. Avaliação do clima organizacional dos servidores técnico-administrativos de uma instituição pública de ensino. ANPAD. 2012.

NEVES, Juliana de Brito Seixas. Gestão do Clima Organizacional, Percepção de Mudança Organizacional e Satisfação do Cliente. Instituto de Pscicologia. Universidade de Brasília: Brasília, 2009.

PIRES, José Calisto de Souza; MACÊDO, Kátia Barbosa. Cultura organizacional em organizações públicas no Brasil. Rio de Janeiro: RAP, 2006. Disponível em: http://www.scielo.br/pdf/rap/v40n1/v40n1a05.pdf Acesso em: 17/12/2015.

RIZZATTI, Gerson. Categorias de análise de clima organizacional em universidades federais brasileiras. Tese de Doutorado. Universidade de Santa Catarina: Florianópolis, 2002. Disponível em: https://repositorio.ufsc.br/bitstream/handle/123456789/84206/186334.pdf?sequence

ROCHA, J. M. C. A Universidade como organização: Espaço de pesquisa e formação em crise. Saberes revista eletrônica, v. 2, p. 1-10, 2014.

RUIZ, João Álvaro. Metodologia Científica: guia para eficiência nos estudos. 5. ed. São Paulo: Atlas, 2002. p. 50-59, jan./jun. 2011.

SAMPAIO, K. R. A gestão da qualidade nas instituições de ensino superior. Faculdade Cearense em Revista, $\quad$ v. $\quad 8, \quad$ p. $1, \quad 2014 . \quad$ Disponível em: http://www.faculdadescearenses.edu.br/revista2/edicoes/vol8-2-2014/artigo1.pdf Acesso em: fevereiro/2016. 
SCHACKOW, Adilson. Estratégia Empresarial: um estudo de caso envolvendo clima organizacional em uma universidade pública. 2008. Monografia. Universidade do Estado de Santa Catarina. 2008.

SILVA, F. L. Reflexões sobre o conceito e a função da universidade pública. Estudos Avançados. São Paulo, v. 42, p. 295-304, 2001. Disponível em: file://C:/Users/jos\%C3\%A9\%20Gomes/Downloads/9807-12484-1-PB\%20(1).pdf Acesso em: 05/03/2016.

SIQUEIRA, Mirlene Maria Matias (org.). Medidas do comportamento organizacional: ferramentas de diagnóstico e de gestão. Porto Alegre: Artmed, 2008. 344p.

SOUSA, Jorgiane Suelen; GARCIA, Fernando Coutinho. Clima Organizacional: Um estudo de caso em uma rede de farmácias no interior de Minas Gerais. Gestão e Regionalidade - Vol. 27. N. 79 - janabr/2011. Disponível em: seer.uscs.edu.br/index.php/revista_gestao/article/viewFile/917/921 Acesso: 03/05/2016.

\section{Como citar este artigo (Formato ABNT):}

BARROS, J.F.A.; BARBOSA, M.A.C. A Relação entre Clima Organizacional e a Prestação do Serviço de Qualidade na Universidade Pública. Id on Line Revista Multidisciplinar e de Psicologia, Julho de 2016, vol.10, n.30, Supl 2, p. 25-39. ISSN 1981-1179.

Recebido: 13/05/2016.

Aceito: 24/05/2016 